\title{
Achalasia management: the South American viewpoint
}

\author{
Fernando A.M. Herbella, Leonardo M. Del Grande \\ Department of Surgery, Escola Paulista de Medicina, Federal University of São Paulo, Sao Paulo, SP 04037-003, Brazil.
}

Correspondence to: Dr. Fernando A.M. Herbella, Department of Surgery, Escola Paulista de Medicina, Rua Diogo de Faria 1087 cj 301 , Sao Paulo, SP 04037-003, Brazil. E-mail: herbella.dcir@epm.br

How to cite this article: Herbella FAM, Del Grande LM. Achalasia management: the South American viewpoint. Mini-invasive Surg 2017;1:115-6.

Article history: Received: 20 Jul 2017 Accepted: 21 Jul $2017 \quad$ Published: 30 Sep 2017

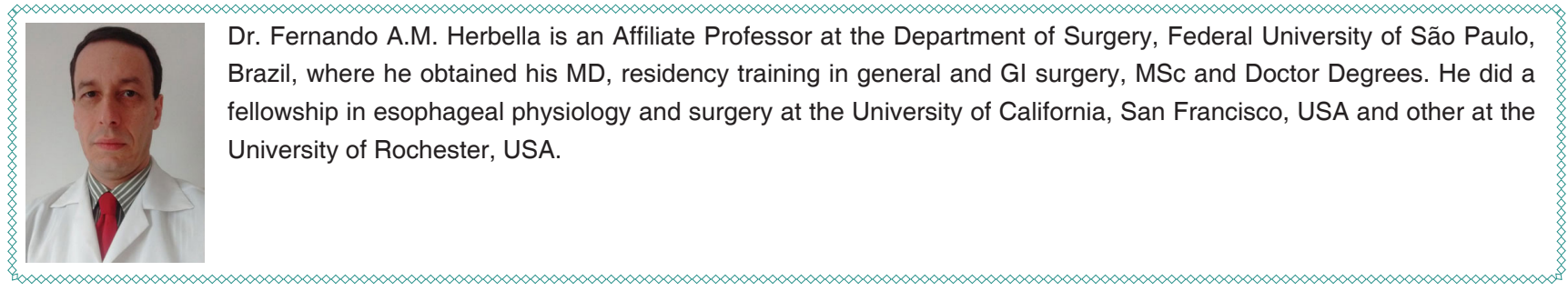

Achalasia is usually quoted as a rare primary esophageal disorder with an unknown etiology. ${ }^{[1]}$ This rarity leads to frequent misdiagnosis as shown by high rate of patients with achalasia referred for antireflux surgery. ${ }^{[2]}$ The two affirmatives that achalasia is rare and lacks an etiology; however, may not be true in South America. In this continent, a local disease Chagas disease or American trypanosomiasis - caused by the inoculation of a parasite through a bug bite leads to an esophagopathy almost indistinguishable from idiopathic achalasia found in other continents, as shown in the paper by Dr. Dantas in this seminar.

Chagas disease currently affects 5-18 million people and an estimated $15-20 \%$ will develop Chagasic esophagopathy. ${ }^{[3]}$ More than this, autochthonous cases of Chagas disease have been reported up to Southern United States ${ }^{[4]}$ and an uncountable number of immigrants carry the disease worldwide. ${ }^{[5]}$ This high incidence of the disease in endemic areas brought a large experience in the management of these patients by South American gastroenterologists and surgeons. Unfortunately, most of this experience is published in local languages making it grey literature for international readers.

Despite several similarities, Chagas disease esophagopathy is characterized by massive dilatation of the esophagus a finding rare in idiopathic achalasia. ${ }^{[6]}$ The treatment for non-advanced achalasia is well established and based on cardiomyotomy (surgical or recently endoscopic) or forceful dilatation of the cardia. ${ }^{[7]}$ The therapy for end-stage disease is; however, controversial and the familiarity of these conditions by South American physicians may be useful. Some unconventional or long-forgotten surgical

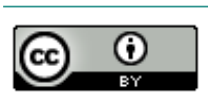

This is an open access article licensed under the terms of Creative Commons Attribution 4.0 International License (https://creativecommons.org/licenses/by/4.0/), which permits unrestricted use, distribution, and reproduction in any medium, as long as the original author is credited and the new creations are licensed under the identical terms.

For reprints contact: service@oaepublish.com

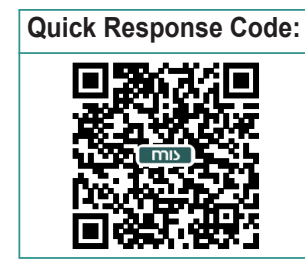

(C) The author(s) 2017 
procedures are still in use in Brazil and some surgeons acquired a large experience with these techniques. Esophageal resection is also a popular choice for dilated megaesophagi.

This seminar reflects the lessons learned by different Brazilian centers highly experienced in the treatment of Chagas disease esophagopathy. Different treatment options are discussed in the light of personal experiences emphasizing aspects not frequently adopted by North American and European surgeons. ${ }^{[8]}$

\section{DECLARATIONS}

\section{Authors' contributions}

Conception and design, writing the manuscript, review of the final version: F.A.M. Herbella

Writing the manuscript, review of the final version: L.M. Del Grande

\section{Financial support and sponsorship}

None.

\section{Conflicts of interest}

There are no conflicts of interest.

Patient consent

Not applicable.

\section{Ethics approval \\ Not applicable.}

\section{REFERENCES}

1. Patti MG, Herbella FA. Achalasia and other esophageal motility disorders. J Gastrointest Surg 2011;15:703-7.

2. Andolfi C, Bonavina L, Kavitt RT, Konda VJ, Asti E, Patti MG. Importance of esophageal manometry and $\mathrm{pH}$ monitoring in the evaluation of patients with refractory gastroesophageal reflux disease: a multicenter study. J Laparoendosc Adv Surg Tech A 2016;26:548-50.

3. Stanaway JD, Roth G. The burden of Chagas disease: estimates and challenges. Glob Heart 2015;10:139-44.

4. Gorchakov R, Trosclair LP, Wozniak EJ, Feria PT, Garcia MN, Gunter SM, Murray KO. Trypanosoma cruzi infection prevalence and bloodmeal analysis in triatomine vectors of chagas disease from rural peridomestic locations in Texas, 2013-2014. J Med Entomol 2016;53:911-8.

5. Antinori S, Galimberti L, Bianco R, Grande R, Galli M, Corbellino M. Chagas disease in Europe: a review for the internist in the globalized world. Eur J Intern Med 2017; doi: 10.1016/j.ejim.2017.05.001.

6. Herbella FA, Oliveira DR, Del Grande JC. Are idiopathic and Chagasic achalasia two different diseases? Dig Dis Sci 2004;49:353-60.

7. Herbella FA, Moura EG, Patti MG. Achalasia 2016: treatmen alternatives. J Laparoendosc Adv Surg Tech A 2017;27:6-11.

8. Herbella FA, Aquino JL, Stefani-Nakano S, Artifon EL, Sakai P, Crema E, Andreollo NA, Lopes LR, de Castro Pochini C, Corsi PR, Gagliardi D, Del Grande JC. Treatment of achalasia: lessons learned with Chagas' disease. Dis Esophagus 2008;21:461-7. 